\title{
Evaluating the effects of PIRAC nitrogen-diffusion treatments on the mechanical performance of $\mathrm{Ti}-6 \mathrm{Al}-4 \mathrm{~V}$ alloy
}

\author{
T. Bonello a, J.C. Avelar-Batista Wilson ${ }^{\text {b }}$, J. Housden ${ }^{\text {b }}$, E.Y. Gutmanas ${ }^{\text {c }}$, I. Gotman ${ }^{\text {, }}$ \\ A. Matthews ${ }^{\mathrm{d}}$, A. Leyland ${ }^{\mathrm{d}}$, G. Cassar ${ }^{\mathrm{a}, *}$ \\ a Department of Metallurgy and Materials Engineering, University of Malta, MSD 2080, Malta \\ ${ }^{\mathrm{b}}$ Wallwork Tecvac R\&D, Buckingway Business Park, Swavesey, Cambridge CB24 4UG, UK \\ ${ }^{\mathrm{c}}$ Department of Materials Science and Engineering, Technion - Israel Institute of Technology, Haifa 32000, Israel \\ ${ }^{\mathrm{d}}$ Department of Materials Science and Engineering, University of Sheffield, Sir Robert Hadfield Building, Mappin St., Sheffield S1 3JD, UK
}

\section{A R T I C L E I N F O}

\section{Article history:}

Received 22 June 2014

Received in revised form

10 September 2014

Accepted 11 September 2014

Available online 19 September 2014

Keywords:

PIRAC

Ti-6Al-4V

Rotating-bending fatigue

Electron backscatter diffraction

\begin{abstract}
A B S T R A C T
Powder Immersion Reaction Assisted Coating (PIRAC) is a relatively simple nitrogen diffusion based process which has been proposed as a technique capable of considerable improvements in the tribological performance of ceramics and metals alike; however, the necessary exposure of the substrate material to high temperatures for several hours may have an adverse effect on the bulk properties of materials such as titanium alloys. The effect of PIRAC treatments on the bulk metallography and mechanical properties of Ti-6Al-4V has been studied. Following PIRAC nitrogen-diffusion treatment, studies using X-ray diffraction and cross-sectional microscopy have shown evidence of the formation of a thin $(\sim 1.4 \mu \mathrm{m}) \mathrm{TiN} / \mathrm{Ti}_{2} \mathrm{~N}$ layer, together with the presence of some $\mathrm{Ti}_{3} \mathrm{Al}$ intermetallic phase. Semilogarithmic $S-N$ plots show a deleterious effect after PIRAC treatment in terms of material cyclic fatigue strength, particularly at higher treatment temperatures. Samples processed at $800{ }^{\circ} \mathrm{C}$ for $4 \mathrm{~h}$ however exhibit better fatigue performance than others treated at lower temperatures for longer nitriding times. Fractographic inspection has shown that fatigue cracks originate at (or near) the surface for the untreated Ti-alloy and from the subsurface regions following diffusion treatment, owing to the build-up of compressive stresses in the latter, which hinder crack propagation.
\end{abstract}

(c) 2014 Elsevier B.V. All rights reserved.

\section{Introduction}

Titanium alloys are being increasingly used because of their excellent physical properties including low density, good strengthto-weight ratio and superior corrosion resistance; however, the range of mechanical applications for this alloy is often limited by poor tribological performance. The latter is attributed to low hardness values, high friction coefficient, poor abrasive wear resistance and the inefficacy of commonly available lubricants [1-3].

The application of surface engineering techniques can serve to significantly improve the tribological performance of such alloys by promoting the formation of (for example) a hard nitride ceramic coating (or a diffusionally generated nitride compound layer) at the surface. Nitriding treatments have been widely used in many industrial applications to improve the surface properties of metals and metal alloys. A number of nitrogen diffusion techniques are known to produce TiN on titanium alloys to improve hardness and wear resistance while also reducing friction. These include chemical

\footnotetext{
* Corresponding author. Tel.: +356 2340 2140; fax: +356 21343577.

E-mail address: glenn.cassar@um.edu.mt (G. Cassar).
}

vapour deposition (CVD) and reactive physical vapour deposition (PVD) [4-7]. However these processes deposit a coating on the substrate which forms weak metallurgical bonds upon interacting with a substrate, thus producing a coating which may be susceptible to delamination and premature failure [7]. Conversely, thermochemical treatments used to produce TiN are known to alter the microstructure of the bulk substrate material [8]. This is the class of treatments which is mostly used to treat titanium alloys (especially gas or plasma nitriding), while Powder Immersion Reaction Assisted Coating (PIRAC) nitrogen-diffusion is a relatively recent addition to these thermochemical treatments.

Shenhar et al. [9] have shown that subjecting titanium alloys to PIRAC treatment results in an increase in hardness and loadsupporting capabilities, excellent nitride-substrate adhesion and overall considerable improvements in terms of tribological performance.

In this study, the effect of the PIRAC process on the bulk metallography and resulting surface mechanical characteristics of the titanium alloy $\mathrm{Ti}-6 \mathrm{Al}-4 \mathrm{~V}$ were investigated. In the following sections, the processing parameters used, the characterisation methods and the fatigue tests utilised will be detailed. Specifically, X-ray diffraction (XRD), scanning electron microscopy (SEM), indentation testing, electron backscatter diffraction (EBSD) techniques 
and rotating-bending fatigue tests were used to determine PIRAC processing parameters that result in an adequate increase in hardness accompanied by minimal fatigue strength reduction following treatment.

\section{Material and experimental details}

\subsection{Material}

The material used in this work is an $\alpha+\beta$ titanium alloy Ti-6Al4V (ASTM Grade 5) supplied by Timetal. This alloy is composed of 5.5-6.75 wt\% $\mathrm{Al}$ and $3.5-4.5 \mathrm{wt} \% \mathrm{~V}$ and has a beta transus temperature of $996 \pm 14^{\circ} \mathrm{C}$. The alloy was subjected to millannealing at $650{ }^{\circ} \mathrm{C}[10]$. Flat specimens were polished using conventional metallographic techniques to a mean areal surface roughness $\left(S_{a}\right)$ value of $0.081 \pm 0.005 \mu \mathrm{m}$. These samples were used for all analysis carried out except for rotating-bending fatigue tests. Rotating-bending fatigue specimens were finished using a $1 \mu \mathrm{m}$ diamond suspension to achieve an axial mean roughness $R_{a}$ of $0.11 \pm 0.01 \mu \mathrm{m}$. The base material was PIRAC-treated at 700 $900{ }^{\circ} \mathrm{C}$ for various durations.

To characterise the microstructure and texture, samples were hot mounted in conductive Bakelite and subsequently ground using $\mathrm{SiC}$ abrasive papers up to the 2500 mesh size $(8.4 \pm 0.5 \mu \mathrm{m}$ grit size). The samples were then polished using a polishing cloth in combination with a $3 \mu \mathrm{m}$ polycrystalline diamond spray and given a final polish using a mixture of $90 \mathrm{vol} \%$ colloidal silica and $10 \mathrm{vol} \%$ hydrogen peroxide. All samples were then ultrasonically cleaned in acetone and finally dried using compressed air. For compound layer thickness measurements, the sample preparation procedure was similar but, prior to hot mounting, the samples were nickel-plated for edge retention using an electroless deposition "EdgeMet" kit (Buehler).

\subsection{PIRAC nitrogen-diffusion}

The reactive diffusion-based PIRAC process was originally developed to treat non-oxide ceramics (e.g., $\mathrm{Si}_{3} \mathrm{~N}_{4}, \mathrm{SiC}, \mathrm{B}_{4} \mathrm{C}$ ) with coatings of the corresponding transition metal compounds (i.e. silicides, nitrides and carbides) [11,12] but was subsequently modified to develop a nitriding technique for metals [7]. PIRAC-based nitrogen diffusion treatment of Ti-6Al-4V samples is achieved by furnace annealing the samples at $700-900{ }^{\circ} \mathrm{C}$ in sealed containers made of a $50 \mu \mathrm{m}$ thick chromium-rich (27 wt\% Cr) stainless steel foil, the container being packed with $\mathrm{Cr}_{2} \mathrm{~N}$ powder which serves as a nitrogen gas source (shown schematically in Fig. 1).

At high annealing temperatures, $\mathrm{Cr}$ from the steel container reacts with the atmospheric oxygen forming a very stable $\mathrm{Cr}$ oxide, $\mathrm{Cr}_{2} \mathrm{O}_{3}$. This reaction prevents further oxygen penetration through the container walls. During this process an $\mathrm{O}_{2}$-pressure not exceeding $10^{-5} \mathrm{~Pa}\left(10^{-7} \mathrm{Torr}\right)$ is maintained inside the container without the application of any vacuum pumps [13]. At the same time, monoatomic nitrogen $(\mathrm{N})$ can easily diffuse through the container walls due to the rather low affinity to $\mathrm{Cr}$ (which is the only nitrideforming element present in the foil). Additional monoatomic nitrogen is provided by decomposition of a relatively unstable $\mathrm{Cr}_{2} \mathrm{~N}$ nitride present in the form of powder inside the container. In both processes, nascent monatomic nitrogen is liberated creating a nitrogen pressure inside the container. The highest vacuum pressure that can be obtained in this experimental setup is the equilibrium pressure of $\mathrm{Cr}_{2} \mathrm{~N}$ formation at the corresponding temperature $\left(\sim 200 \mathrm{~Pa}\right.$ at around $\left.1000{ }^{\circ} \mathrm{C}\right)$. Reactive diffusion of the active monatomic nitrogen results in the formation of various nitrides on Ti-based alloys such as Ti-6Al-4V. As the substrate is directly involved in the nitride-forming process, PIRAC nitrogendiffusion is akin to oxide film formation on metals and metal alloys,

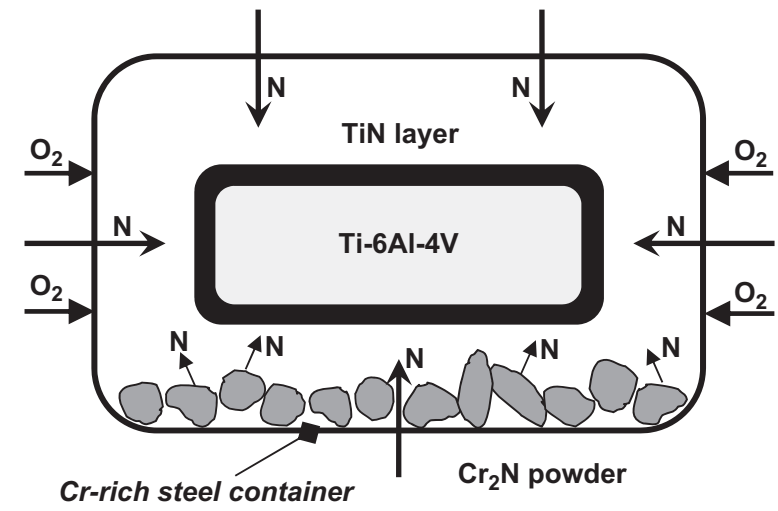

Fig. 1. Diagram showing PIRAC nitrogen-diffusion process employed in this work $[7,11]$.

resulting in excellent nitride-substrate adhesion. In addition, PIRAC nitrogen-diffusion is not a line-of-sight process and therefore allows uniform treatment of complex shape components.

\subsection{Characterisation}

X-ray diffraction using a Grazing Incidence Asymmetric Bragg (GIAB) geometry was used for phase identification. A Rigaku Ultima IV XRD machine with a CuKo-source and a permanently installed Cross Beam Optics (CBO) unit was operated at $45 \mathrm{kV}$ and $40 \mathrm{~mA}$. Scans were performed using an incidence angle of $3^{\circ}$, with a step size of $0.02^{\circ}$ and a dwell time of $4 \mathrm{~s} / \mathrm{step}$, over a $2 \theta$ range of $20-90^{\circ}$. As estimated by the AbsorbDX software, at an incident angle of $3 \circ, 90 \%$ of the diffracted signal originated from the top 0.40 and $0.35 \mu \mathrm{m}$ for untreated and PIRAC-treated Ti$6 \mathrm{Al}-4 \mathrm{~V}$ coupons, respectively. Diffraction peaks were indexed according to JCPDS phase spectra provided by the International Centre of Diffraction Data (ICDD).

Knoop microindentation hardness measurements were performed using a Mitutoyo MVK-H2 machine. To select an appropriate load the roughest sample was tested with increasing load from $25 \mathrm{gf}(1 \mathrm{gf}=9.81 \mathrm{mN})$ upwards, until a clear imprint of the indenter was obtained. Based on these preliminary results, the machine was set to a pre-set load of 50 gf using a 20 second dwell time. The diagonal length of indentation and corresponding hardness were noted for multiple indents performed on each sample.

Nanoindentation hardness measurements were performed using a MicroMaterials NanoTest equipped with a $120^{\circ}$ Berkovich three-sided pyramid diamond tip indenter. Load-controlled tests were performed with the maximum load set at $8 \mathrm{mN}$ using a loading/unloading rate of $0.2 \mathrm{mN} \mathrm{s}^{-1}$. The initial preload was set to $0.1 \mathrm{mN}$ to avoid any surface slippage and an array of $5 \times 8$ indentations was constructed with indentation offsets of $30 \mu \mathrm{m}$ in both $z$ and $y$ directions. A dwell time of $1 \mathrm{~s}$ was used at the maximum load. The test was performed at a stable $24{ }^{\circ} \mathrm{C}$ and only once thermal equilibrium was reached. The Oliver and Pharr method described in [14] was used to determine the Young's Modulus, E, for untreated and PIRAC-treated Ti-6Al-4V. The Poisson's ratio, $v$, of TiN was taken to be 0.25 [15] while that of Ti-6Al-4V was taken as 0.31 [10].

Electron backscatter diffraction (EBSD) was used to determine grain size and texture [16]. It is widely known that the mechanical properties of a material are strongly dependent on the grain size [17]. EBSD was carried out using a Carl Zeiss Merlin scanning electron microscope equipped with an EBSD/EDX Ametek detector, operated at $20 \mathrm{kV}$ and $2 \mathrm{nA}$ set a working distance of $15 \mathrm{~mm}$. The sample inclination was set to $68^{\circ}$ to the sample surface. A grid size 
of $50 \mu \mathrm{m} \times 50 \mu \mathrm{m}$ was used to scan untreated Ti-6Al-4V and PIRAC treatments performed at $800{ }^{\circ} \mathrm{C}$ for $4 \mathrm{~h}$ and $900{ }^{\circ} \mathrm{C}$ for $2 \mathrm{~h}$. A scan area of $100 \mu \mathrm{m} \times 100 \mu \mathrm{m}$ was mapped for the PIRAC treatment performed at $700{ }^{\circ} \mathrm{C}$ for $48 \mathrm{~h}$ due to random sporadic growth in some grains. Mapping was carried out with the use of TSL OIM Analysis 5.31 software.

Surface roughness readings were taken using a Zemetrics ZeScope optical surface profiler with interferometric optical focus scanning to a vertical resolution of $0.1 \mathrm{~nm}$. Five measurements (at random positions and orientations) were recorded to calculate an average $S_{a}$ value (i.e. the arithmetic average of 3D roughness measurements). The 3D roughness measurements were performed over an area covering $533 \times 714 \mu \mathrm{m}^{2}$.

\subsection{Rotating-bending fatigue testing}

A total of 60 samples were machined to an hourglass geometry according to ISO 1143 [18] as shown in Fig. 2, polished to a smooth finish and subsequently PIRAC-treated. Plain fatigue tests were carried out, based on the rotating-bending fatigue models originally described by Wöhler [19] using an Italsigma 2TM831 four-point loading rotating-bending fatigue test machine with a frequency of $60 \mathrm{~Hz}(100 \mathrm{rev} / \mathrm{s})$ and a loading ratio $R$ of -1 . The adopted test procedure, including mounting routine, was performed in accordance to that outlined in the relevant standard [18]. Tests were terminated in one of two manners: either when the sample broke or when the test had completed $10^{7}$ cycles. Each batch of samples consisted of 15 specimens for each set of processing variables. Due to the number of available samples, $\left(n_{s}=15\right)$, the median method in combination with the staircase method was used to construct $S-N$ plots. A minimum of eight specimens were used for the determination of fatigue life and the remaining fatigue specimens were used to determine the fatigue limit. To obtain some level of percentage replication (PR), more than one specimen was used at a given stress amplitude. For the four batches studied in this work, a PR ranging from $46 \%$ to $85 \%$ was obtained for different stress levels, $L$, ranging from 7 to 10 in each batch [20].

The fatigue endurance limit is the maximum stress that a material can withstand for at least $10^{7}$ cycles (this limit appears as a plateau on the $S-N$ plot). It is difficult to estimate this value for any $S-N$ plot but it is usually taken to be the first instance where a microcrack develops into a larger crack. This is dependent on several factors including microcrack location, orientation, size and number of cracks [21].

Table 1 provides a summary of the processing parameters employed throughout this work. The temperature and duration of the process were chosen to allow for comparison of treatments which were expected to generate similar nitride layer thicknesses. Following fatigue testing, some failed coupons were selected. The fracture surfaces were viewed using a combination of optical microscopy and scanning electron microscopy.

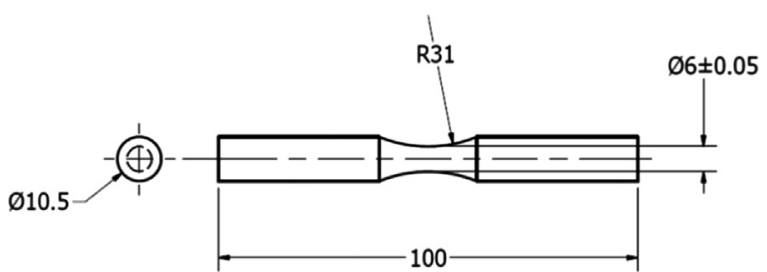

Fig. 2. Hourglass geometry of as-received rotating fatigue test samples according to ISO 1143.
Table 1

Untreated and PIRAC treated Ti-6Al-4V samples with fatigue test geometry.

\begin{tabular}{cccc}
\hline Designation & Sample size, $n_{s} \begin{array}{l}\text { PIRAC treatment processing } \\
\text { parameters }\end{array}$ \\
\cline { 3 - 4 } & & Temperature $\left({ }^{\circ} \mathbf{C}\right)$ & Duration $(\mathbf{h})$ \\
\hline Untreated Ti-6Al-4V & 15 & - & - \\
$700^{\circ} \mathrm{C} / 48 \mathrm{~h}$ & 15 & 700 & 48 \\
$800^{\circ} \mathrm{C} / 4 \mathrm{~h}$ & 15 & 800 & 4 \\
$900^{\circ} \mathrm{C} / 2 \mathrm{~h}$ & 15 & 900 & 2 \\
\hline
\end{tabular}

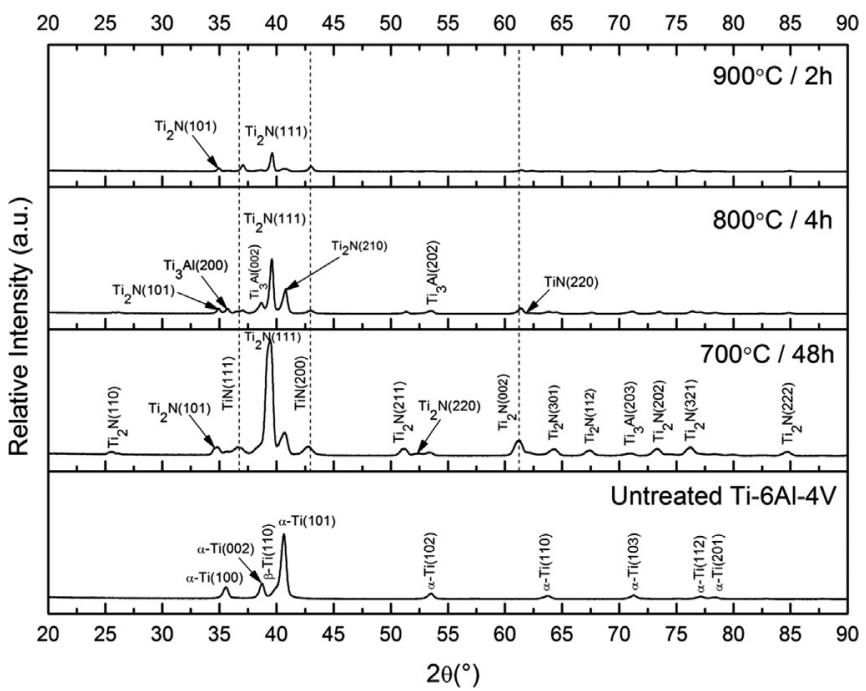

Fig. 3. GIXRD with an incidence angle of $3^{\circ}$ of Ti-6Al-4V and PIRAC nitrogendiffusion treated $\mathrm{Ti}-6 \mathrm{Al}-4 \mathrm{~V}$ at different processing parameters.

\section{Results and discussion}

\subsection{Grazing Incidence X-ray Diffraction (GIXRD) analysis}

GIXRD patterns of untreated and PIRAC-treated Ti-6Al-4V specimens are shown in Fig. 3. The phase constituents of Ti-6Al-4V were indexed to hexagonal $\alpha$-Ti (\#005-0682) and cubic $\beta$-Ti (\#0894913). As expected, the high intensity peaks for Ti-6Al-4V correspond to $\alpha$-Ti which is the major phase of this alloy in its annealed condition. Only one minor peak of $\beta$-Ti was detected.

Following PIRAC diffusion treatment, new peaks apparent in the GIXRD patterns correspond to the titanium nitrides - cubic $\delta$ TiN (\#038-1420) and tetragonal $\varepsilon-\mathrm{Ti}_{2} \mathrm{~N}$ (\#017-0386), and to intermetallic hexagonal $\mathrm{Ti}_{3} \mathrm{Al}$ (\#052-0859). The substrate peaks ( $\alpha$ - and $\beta$-Ti) disappear from the pattern suggesting that these phases are suppressed to below the compound layer; i.e. beyond the depth sampled using GIXRD.

The predominant TiN peaks are those with hkl crystallographic plane indices (111) and (200) located at $36.5-36.8^{\circ}$ and $42.6-42.9^{\circ}$ respectively with no significant angular shifting (with respect to the PDF standard) detected. From Fig. 3, it is clear that the PIRAC processing parameters affect the growth of these phases; for both TiN peaks, the largest growth is observable for the highest treatment temperature at $900{ }^{\circ} \mathrm{C}$. The intensity of the $\mathrm{Ti}_{2} \mathrm{~N}(111)$, detected at approximately $39.4-39.5^{\circ}$, diminishes with higher nitriding temperatures, however it is still the predominant peak, indicating preferential growth on the $\mathrm{Ti}_{2} \mathrm{~N}(111)$ plane which is favoured mostly by the $700{ }^{\circ} \mathrm{C}, 48 \mathrm{~h}$ treatment. At these treatment conditions, the $\mathrm{Ti}_{2} \mathrm{~N}(101)$ and $\mathrm{Ti}_{2} \mathrm{~N}(200)$ planes are of lower intensity but still mostly favoured by these processing conditions, 
indicating that, following this treatment, the surface is mostly composed of $\varepsilon-\mathrm{Ti}_{2} \mathrm{~N}$.

One would expect the high temperature treatment to exhibit the largest concentrations of $\mathrm{TiN}$ and $\mathrm{Ti}_{2} \mathrm{~N}$. However the $900{ }^{\circ} \mathrm{C}$, $2 \mathrm{~h}$ processing conditions are compromised by the short exposure time such that nitrogen diffusion treatments at $700{ }^{\circ} \mathrm{C}, 48 \mathrm{~h}$ followed by $800^{\circ} \mathrm{C}, 4 \mathrm{~h}$ exhibit the next largest peaks. Similar observations have been reported by Fouquet et al. [22] for plasma nitriding processes.

The $\mathrm{Ti}_{3} \mathrm{Al}$ phase was also reported in PIRAC literature by Shenhar et al. [7,9] for treated Ti-6Al-4V alloy. This phase was detected in small quantities owing to the fact that the $\mathrm{Ti}_{3} \mathrm{Al}$ phase is located below the primary constituents of the compound layer: $\delta$-TiN and $\varepsilon-\mathrm{Ti}_{2} \mathrm{~N}$. It has been demonstrated that, following diffusion of interstitial elements such as oxygen and nitrogen, aluminium diffuses 'uphill' leaving a depleted region adjacent to the interface with the nitrogen-rich compound layer [7,23]. As the incident X-ray beam penetrates into the surface, most of the diffracted signal originates from the $\delta$ and $\varepsilon$ nitride layers. Indeed, higher intensity peaks have been reported for $\mathrm{Ti}_{3} \mathrm{Al}$ using a conventional $\theta-2 \theta$ Bragg-Brentano setup [7].

\subsection{Compound layer thickness}

PIRAC nitrogen-diffusion treatment of Ti-6Al-4V yielded three main distinguishable layers: the compound layer $(\mathrm{CL})$, the nitrogen stabilised $\alpha$-case and regions of $\mathrm{Ti}_{3} \mathrm{Al}$ intermetallic precipitation (Fig. 4). The surface layers visible in all micrographs (Fig. 4a-c) were found to be in accordance with those observed by Lee et al. in [24] and Shenhar et al. [7,9]; however, particularly for shorter nitrogen exposure times, the $\mathrm{Ti}_{3} \mathrm{Al}$ phase is not continuous. This phase extends throughout the diffusion zone until the beta phase appears. As expected, based on PIRAC pretrials, the resulting compound layer thicknesses at the different processing parameters were similar.

It has been reported that the rate of nitrogen diffusion in the titanium $\alpha$-phase is 30 times higher than for nitride compounds such as $\mathrm{TiN}$ and $\mathrm{Ti}_{2} \mathrm{~N}$; the formation of compound layers of these titanium nitride phases thus effectively impedes further nitrogen diffusion in the bulk [5], which in turn may dictate longer (or higher temperature) treatments for improved efficacy and thicker compound layer formation. Indeed, according to the Arrheniustype relationship governing nitrogen diffusion, and Fick's second law for non-steady-state diffusion, the treatment temperature is a dominant parameter. This explains why a long $48 \mathrm{~h}$ treatment was necessary at $700{ }^{\circ} \mathrm{C}$ (to compensate for the relatively low temperature employed), such that the compound layer thickness only varied marginally (by $0.1 \mu \mathrm{m}$ and $0.2 \mu \mathrm{m}$ respectively) from PIRAC treatments carried out at $800{ }^{\circ} \mathrm{C}, 4 \mathrm{~h}$ and $900^{\circ} \mathrm{C}, 2 \mathrm{~h}$.

Thinner nitride compound layers have been reported for shorter nitriding durations owing to the fact that at these exposure times the nitrogen content of the compound layer is approximately 34 at $\% \mathrm{~N}$ for temperatures below $1100{ }^{\circ} \mathrm{C}$. According to the Ti-N phase diagram this nitrogen content is sufficient for $\mathrm{Ti}_{2} \mathrm{~N}$ formation but not TiN [25]. This means that long nitriding times (even at low temperature) allow enough time for the diffusion of sufficient nitrogen to allow the formation of TiN. This phase formation is favoured by the lower temperature treatment $\left(700^{\circ} \mathrm{C}, 48 \mathrm{~h}\right)$ as can be seen in the diffraction pattern (Fig. 3). Indeed, from Fig. 4, a thickness comparable to that of higher temperature treatments was measured.

A temperature increase of $100{ }^{\circ} \mathrm{C}$ (from $700{ }^{\circ} \mathrm{C}$ to $800{ }^{\circ} \mathrm{C}$ ) provides the possibility of significantly reducing the nitriding time (from $48 \mathrm{~h}$ to $4 \mathrm{~h}$ ) to obtain a compound layer thickness of $1.4 \mu \mathrm{m}$ (an approximate $9 \%$ increase in thickness). Increasing the treatment temperature further to $900{ }^{\circ} \mathrm{C}$ (with shorter nitriding time of $2 \mathrm{~h}$ ) results in an approximate thickness increase of $10 \%$ compared to the initial $700{ }^{\circ} \mathrm{C}, 48 \mathrm{~h}$ treatment.

\subsection{Hardness testing}

Knoop microhardness measurements were performed to study the difference in hardness for the various PIRAC nitrogen-diffusion parameters investigated in this work. Table 2 provides a summary of the hardness measurements (converted to GPa) together with the calculated depth of the indentations, which is approximately $1 / 30^{\text {th }}$ of the impression length [26]. In most cases depths sampled by the indenter fall well within the compound layer formed after PIRAC diffusion treatment, the thickness measurements of which are shown in Fig. 4; however, the indenter penetration was still sufficiently large to allow some degree of substrate contribution to the results presented. This was particularly the case for the PIRAC treatment performed at $700{ }^{\circ} \mathrm{C}, 48 \mathrm{~h}$ for which an estimated $20 \%$ of the substrate volume was sampled.

Nanoindentation testing was thus used to determine representative hardness, $H$, Young's Modulus, $E$, and $H / E$ ratios of untreated and PIRAC-treated surfaces. From Table 3, PIRAC nitrogen-diffusion invariably increases the hardness over that of the untreated substrate with the hardness increasing significantly with increasing nitriding temperature. This was confirmed by both nano- and micro-indentation measurements; however, nanoindentation values (see Table 2) are much higher than those obtained from Knoop micro indentation (see Table 3). This is a result of the different scales of indentation; while microindents penetrated deeper into the compound layer, sampling some underlying substrate material, the load of nanoindentation measurements was selected such tat indentation on treated specimens was always less than $150 \mathrm{~nm}$.

Table 3 shows that the material hardness increases with treatment temperature and duration. This is in accordance with the study carried out in [22] for a similar nitriding process. Measured hardness values depend on the compound layer characteristics, including thickness and phase composition. When compared to the untreated Ti-6Al-4V substrate hardness, there is a significant jump in hardness, especially for the higher temperature treatments of $800{ }^{\circ} \mathrm{C}$ and $900{ }^{\circ} \mathrm{C}$. The formation of $\varepsilon-\mathrm{Ti}_{2} \mathrm{~N}$ and the suppression of $\alpha$-Ti phase to below the surface following the treatment (as observed in the diffraction pattern shown in Fig. 3.) leads to a very significant increase in measured hardness. This sharp increase has been previously documented in the literature and it is attributed to (a)

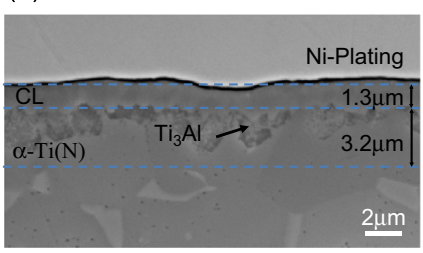

(b)

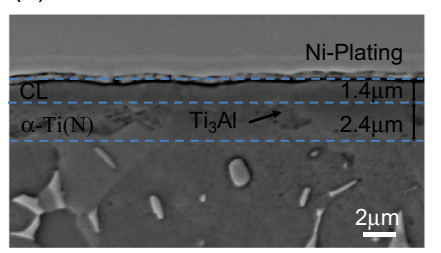

(c)

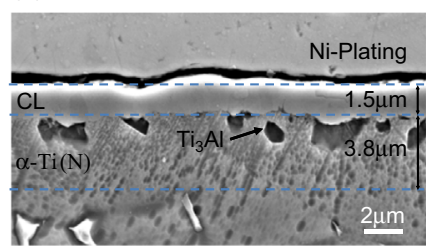

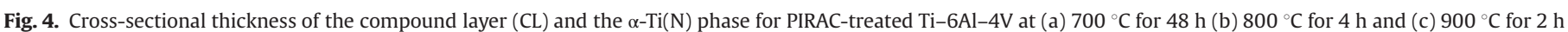
using SEM. 
Table 2

Table showing the measured Knoop microhardness, $H$, and the corresponding depth of impression, $D$, for untreated and PIRAC-treated Ti-6Al-4V.

\begin{tabular}{lccc}
\hline $\begin{array}{l}\text { PIRAC treatment } \\
\text { parameters }\end{array}$ & $\begin{array}{c}\text { Average Knoop } \\
\text { microhardness, } \\
\boldsymbol{H}(\mathbf{G P a})\end{array}$ & $\begin{array}{c}\text { Depth of } \\
\text { impression, } \\
\boldsymbol{D},(\boldsymbol{\mu m})\end{array}$ & $\begin{array}{c}\text { Measured } \\
\text { compound layer } \\
\text { thickness }(\boldsymbol{\mu m})\end{array}$ \\
\hline- & $3.37 \pm 0.10$ & 1.52 & - \\
$700{ }^{\circ} \mathrm{C} / 48 \mathrm{~h}$ & $5.73 \pm 0.63$ & 1.67 & 1.3 \\
$800{ }^{\circ} \mathrm{C} / 4 \mathrm{~h}$ & $9.00 \pm 0.73$ & 0.93 & 1.4 \\
$900{ }^{\circ} \mathrm{C} / 2 \mathrm{~h}$ & $11.98 \pm 2.64$ & 0.82 & 1.5 \\
\hline
\end{tabular}

Table 3

Hardness, $H$, and calculated values of Young's modulus, $E$, and $H / E$ ratio of untreated and PIRAC-treated Ti-6Al-4V.

\begin{tabular}{lcccc}
\hline $\begin{array}{l}\text { PIRAC } \\
\text { treatment } \\
\text { parameters }\end{array}$ & $\begin{array}{c}\text { Hardness, } \\
\boldsymbol{H}(\mathbf{G P a})\end{array}$ & $\begin{array}{c}\text { Average } \\
\text { penetration depth, } \\
\boldsymbol{D}(\mathbf{n m})\end{array}$ & $\begin{array}{c}\text { Young's modulus } \\
\text { of elasticity, } \\
\boldsymbol{E}(\mathbf{G P a})\end{array}$ & $\begin{array}{c}\boldsymbol{H} / \boldsymbol{E} \\
\text { ratio }\end{array}$ \\
\hline- & $4.53 \pm 0.33$ & $228.36 \pm 13.76$ & $154.48 \pm 13.18$ & 0.029 \\
\hline $700{ }^{\circ} \mathrm{C} / 48 \mathrm{~h}$ & $22.14 \pm 3.22$ & $124.56 \pm 9.40$ & $258.28 \pm 23.80$ & 0.071 \\
$800^{\circ} \mathrm{C} / 4 \mathrm{~h}$ & $25.45 \pm 4.30$ & $119.10 \pm 9.72$ & $258.69 \pm 28.28$ & 0.081 \\
$900{ }^{\circ} \mathrm{C} / 2 \mathrm{~h}$ & $26.98 \pm 6.24$ & $110.97 \pm 12.34$ & $321.85 \pm 52.36$ & 0.064 \\
\hline
\end{tabular}

the formation of both the $\delta$-TiN and $\varepsilon-\mathrm{Ti}_{2} \mathrm{~N}$ constituting the nitride case [22]. The TiN/ $/{ }_{2}{ }_{2} \mathrm{~N}$ intensity in GIXRD plots shown in Fig. 3 is not a good indicator as to why the compound layer becomes increasingly harder with temperature and short processing duration. However, $\mathrm{Ti}_{2} \mathrm{~N}$ formation is known to produce layers which are harder $(32.4 \pm 6.6 \mathrm{GPa}$ at approximately $5 \%$ coating penetration) [27] than those documented for TiN (22.6 $\pm 4.6 \mathrm{GPa})$ [28-30] and as such may provide an indirect indication of the compound layer phase composition. It is proposed that, following PIRAC nitrogendiffusion at $700{ }^{\circ} \mathrm{C}$ and $48 \mathrm{~h}$, the total compound layer formation is sufficient to allow indentations to be mostly contained within the near surface nitride $\delta$-TiN which in turn results in hardness values closer to those reported for TiN. While at the higher nitriding temperatures of $800{ }^{\circ} \mathrm{C}$ and $900{ }^{\circ} \mathrm{C}$, the processing durations of $4 \mathrm{~h}$ and $2 \mathrm{~h}$ respectively are sufficiently short to allow predominantly $\mathrm{Ti}_{2} \mathrm{~N}$ formation, thus resulting in slightly higher hardness values as more of the underlying $\mathrm{Ti}_{2} \mathrm{~N}$ is sampled during the indentation test.

The value of Young's Modulus obtained for the untreated Ti$6 \mathrm{Al}-4 \mathrm{~V}$ was found to be higher than the bulk value stated by the manufacturer (Timetal) of 107-112 GPa, with a calculated bulk value of $\sim 154 \mathrm{GPa}$. This can be attributed to the fact that the data sheet value cited is a bulk value, rather than one obtained via nanoindentation methods. As regards the diffusion-treated substrate, $E$ values are in accordance with the estimated 280-620 GPa range measured for $\delta$-TiN [31].

Previous studies [32,33] have reportedly shown that a high coating $H / E$ ratio is conducive to good tribological performance. This means a relatively high coating hardness, $H$, should be complemented by a moderately low Young's Modulus, $E$ - the latter ideally approaching that of the (metallic) substrate. For a nitrided material (where the diffusion treatment can increase the local stiffness of the substrate material) this should result in improved wear resistance and higher toughness [33]. At the same time, if the Young's Modulus, E, of the nitride compound can be matched to that of the (diffusion-treated) substrate, the potential build-up of interfacial stress concentrations can be mitigated [32]. From Table 3, the PIRAC nitrogen-diffusion treatments resulting in the highest $H / E$ ratio are those performed at $800{ }^{\circ} \mathrm{C}$ for $4 \mathrm{~h}$ and $700{ }^{\circ} \mathrm{C}$ for $48 \mathrm{~h}$. These conditions were also found to promote the best tribological behaviour. It would be expected therefore that PIRAC nitriding treatments having low $H / E$ values would perform poorly in comparison to those with high values. Nevertheless, the differences in elastic moduli between the diffusion-treated layer and the bulk substrate material suggest that some degree of interfacial stress formation will occur. The treatments carried out at $700{ }^{\circ} \mathrm{C}$ for $48 \mathrm{~h}$ and $800{ }^{\circ} \mathrm{C}$ for $4 \mathrm{~h}$ present the best match of elastic modulus between the nitride compound layer and the diffusion-treated substrate, whilst the treatment at $900{ }^{\circ} \mathrm{C}$ for $2 \mathrm{~h}$ presents the largest difference in elastic modulus between the nitride compound and the substrate alloy ( $48 \%$ ). The effect of this nitride-substrate $E$ mismatch will be discussed in Section 3.5.

\subsection{Electron backscatter diffraction}

Microstructural examination was performed by EBSD in order to study differences in alpha and beta phase content, orientation and grain size for untreated and PIRAC-treated bulk microstructures. Fig. 5 depicts the sample setup within the vacuum chamber together with the sample reference system.

Preliminary analysis of the EBSD scans was carried out by first generating a phase map in the orientation imaging software for both $\alpha$ and $\beta$ phases. The phases given in Table 4 were given as a fraction of the total scan area.

The highest reported abundance of $\alpha$-phase is for the specimen treated at $700{ }^{\circ} \mathrm{C}$ for $48 \mathrm{~h}$. This is in agreement with bulk microstructural analysis and is attributed to concentrated large $\alpha$-plates with isolated globular $\beta$-deposits dispersed between them. With the increase of PIRAC treatment temperature, the $\beta$-phase is redistributed along the grain boundaries of the $\alpha$-phase, such that fine intergranular $\beta$-deposits can be seen. The abundance of $\beta$ phase increases as the PIRAC treatment temperature is increased. This $\beta$-phase increase is in accordance with the Ti-V phase diagram presented in [8]. The highest treatment temperature of $900{ }^{\circ} \mathrm{C}$ for $2 \mathrm{~h}$ does not exceed the $\beta$-transus temperature of $996 \pm 14{ }^{\circ} \mathrm{C}$ for this titanium alloy, meaning that the bulk material contains an acceptable amount of $\alpha+\beta$ mixture at this treatment temperature.

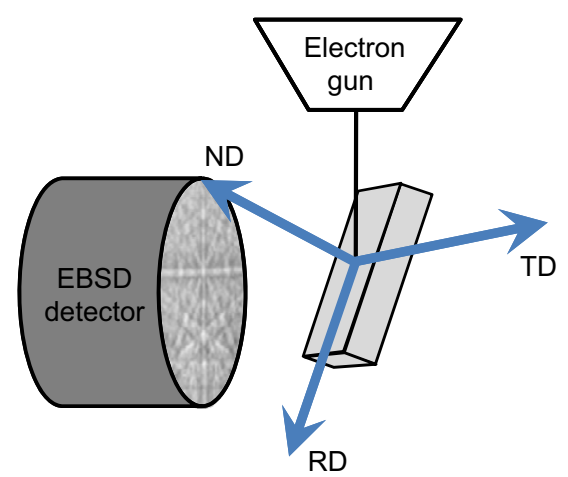

Fig. 5. EBSD setup including incident electron beam, tilted sample at $\sim 70^{\circ}$, sample reference system and diffracted Kikuchi pattern, where ND is the normal direction, $\mathrm{TD}$ is the traverse direction and RD is the rolling direction.

Table 4

Alpha and beta volume fractions calculated from EBSD data.

\begin{tabular}{|c|c|c|c|}
\hline \multicolumn{2}{|l|}{ PIRAC parameters } & \multirow[t]{2}{*}{$\alpha$-Fraction } & \multirow[t]{2}{*}{$\beta$-Fraction } \\
\hline Temperature $\left({ }^{\circ} \mathbf{C}\right)$ & Duration (hrs) & & \\
\hline- & - & 0.994 & 0.006 \\
\hline 700 & 48 & 0.995 & 0.005 \\
\hline 800 & 4 & 0.981 & 0.019 \\
\hline 900 & 2 & 0.967 & 0.033 \\
\hline
\end{tabular}


(a)

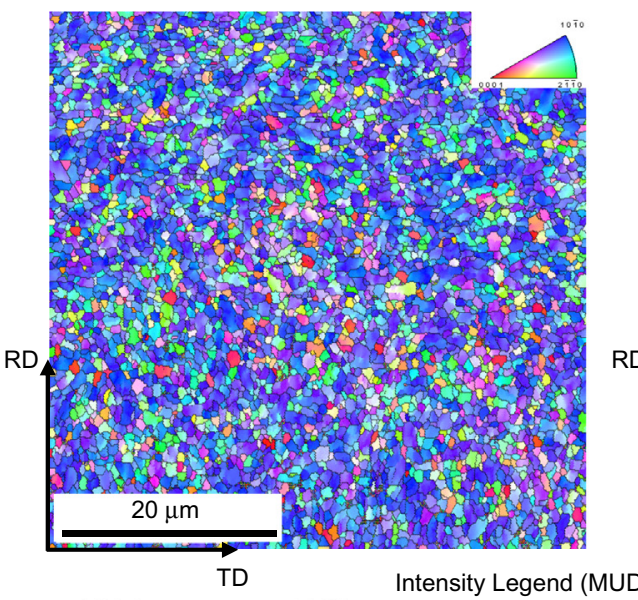

(b)

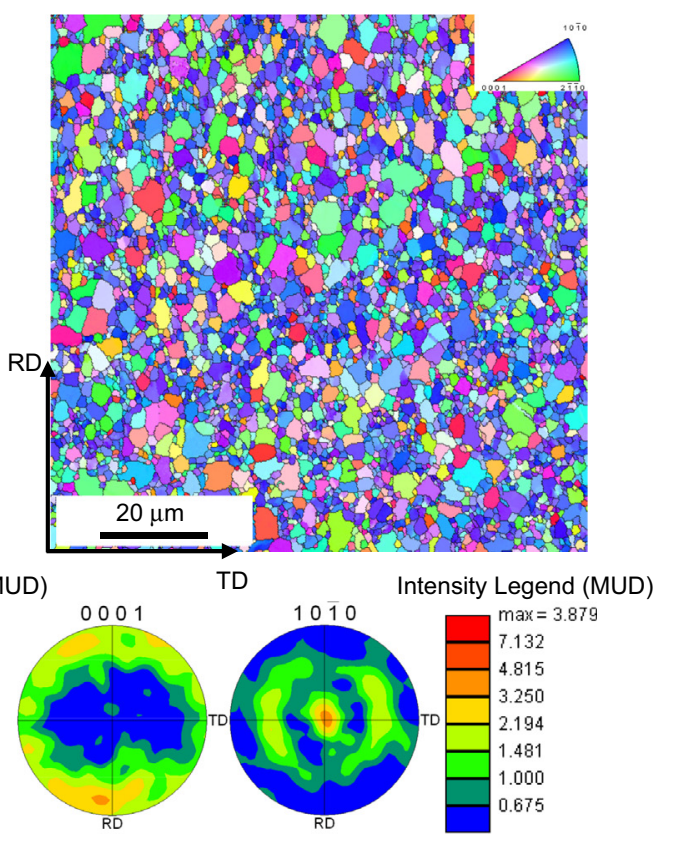

(d)
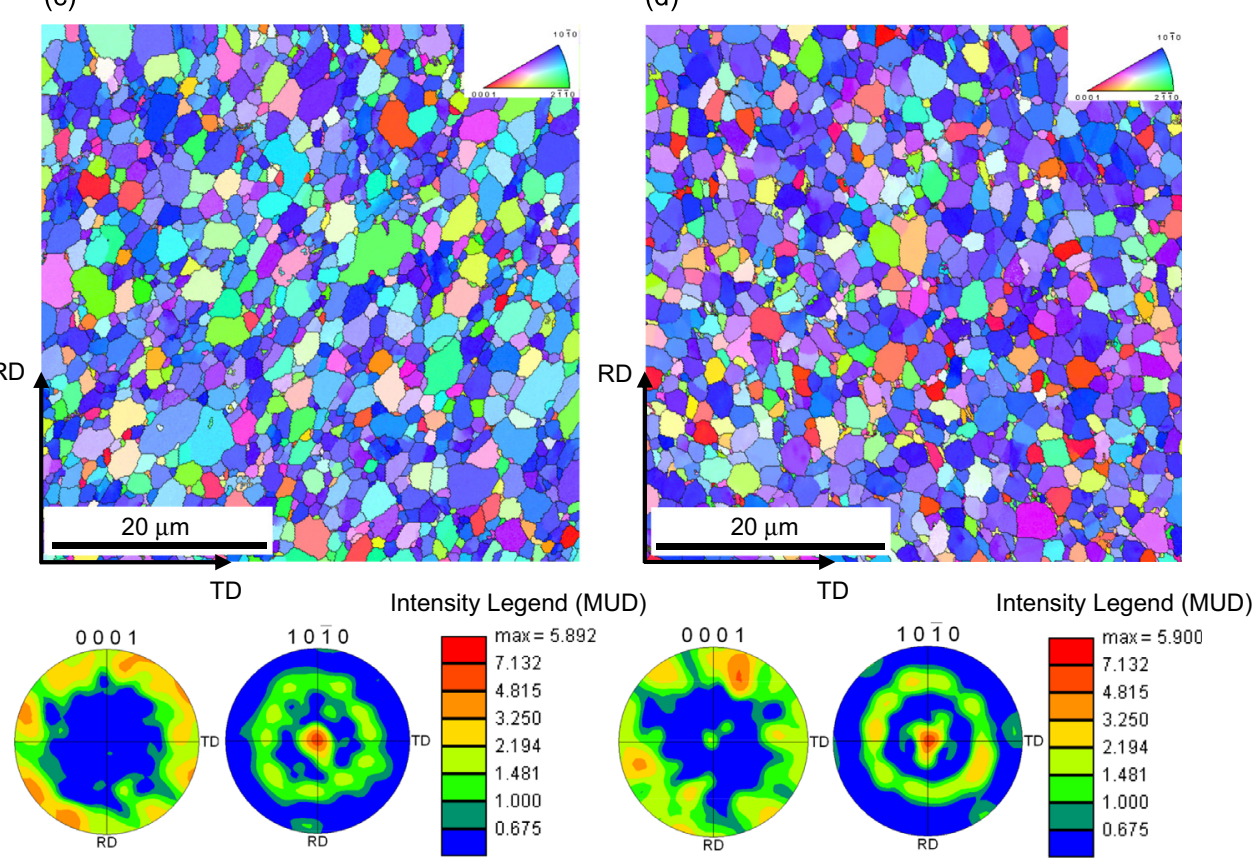

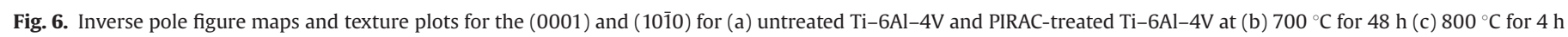
and (d) $900{ }^{\circ} \mathrm{C}$ for $2 \mathrm{~h}$. (For interpretation of the references to colour in this figure, the reader is referred to the web version of this article).

In all cases, the texture provided is for the $\alpha$ phase, as this is the principal constituent of Ti-6Al-4V - with only small quantities of $\beta$-phase, increasing from $0.6 \mathrm{vol} \%$ for the untreated material to 3.3 vol\% for the alloy treated at $900{ }^{\circ} \mathrm{C}$ for $2 \mathrm{~h}$ (see Table 4). Fig. 6 shows the normal-projected Inverse Pole Figure (IPF) maps which are used to determine crystal planes parallel to the normal direction, together with EBSD texture plots which are stereographic projections of given planes (the (0001)and (1010) in this work) in the crystal structure, with respect to the sample reference frame. Texture plots and corresponding contour intervals were obtained using a harmonic series expansion calculation. The normalised texture intensities are expressed in terms of Multiples of Uniform Distribution (MUD) [34]. Both methods provide the user with an indication of the orientation relationship between two coordinate systems: sample and crystal.

Clearly, for untreated Ti-6Al-4V (Fig. 6a) most of the grains present a $\langle 10 \overline{1} 0\rangle$ direction with respect to the sample normal, since a distinct dominant blue hue can be seen from the IPF basic RGB colouring scheme. The texture plot of the (1010) crystallographic plane corroborates this as the cross-sectional surface is characterised by a strong prismatic fibre texture, evidenced by a uniform ring some distance away from the main texture peak. The (0001) texture plot shows poles located some distance away from the transverse direction. Apart from mirroring the uniform ring formed for the (1010) plane, the distribution obtained for the (0001) basal texture plot indicates that most of the grains are 
oriented approximately parallel to the extrusion direction. These texture symmetries have been previously reported in the literature for titanium alloys in the swaged condition [35].

Following PIRAC nitrogen-diffusion treatment at $700{ }^{\circ} \mathrm{C}$ for $48 \mathrm{~h}$ (Fig. 6b) most grains retain their orientation towards the $\langle 1010\rangle$ direction; however, other grains seemingly re-orient themselves. Large grains $(\sim 6.5 \mu \mathrm{m})$ are oriented in entirely opposing directions of the spectrum, characterising the IPF with varying hues. This observation is also reflected in the texture plots as a fibre texture remains present, but is not as strong as for the untreated sample. For the (1010) texture plot a moderate evolution of texture is observable. Two main poles located some distance away from the rolling direction (RD) can be distinguished for the (0001) texture plot - both indicating prismatic texturing. The strongest pole indicates a moderately strong texturing of the (1210) plane while the lower intensity pole shows some texturing of the (1̄120) plane.

The IPF obtained following treatment at $800{ }^{\circ} \mathrm{C}$ (Fig. 6c) indicates moderate texturing towards the $\langle 10 \overline{1} 0\rangle$ direction. A surface normal fibre texture of the (1010) crystallographic plane can be observed. The (0001) texture plot also corroborates this strong prismatic plane orientation as most of the grains have their prismatic plane oriented almost perpendicularly to the normal direction.

Finally, the IPF obtained for the $900{ }^{\circ} \mathrm{C}, 2 \mathrm{~h}$ treatment (Fig. $6 \mathrm{~d}$ ) indicates that a majority of the grains are oriented towards the $\langle 1010\rangle$ direction. Again, texture plots are in agreement with this, since a comparatively uniform ring - indicative of (1010) fibre texture - can be distinguished at the cross-sectional surface. The main pole for the (0001) texture plot is aligned to the $\langle 11 \overline{2} 0\rangle$ direction. This implies that the post-processed material would be largely susceptible to basal slip. Basal $(0001)\langle 112 \overline{2} 0\rangle$ slip has been identified as a possible slip system for hcp materials with a low $c / a$ ratio such as titanium - but it is not the only available slip system. In fact, the principal system responsible for the activation of slip is the prismatic $(00 \overline{1} 0)\langle 11 \overline{2} 0\rangle$ system. The combination of this prismatic slip system and secondary basal slip systems (as opposed to having a single slip system) will contribute to more complex deformation modes when a mechanical stress is applied to the base material [36].

In all cases, upon PIRAC treatment the grains re-orient themselves. The maximum texture intensity is measured at 7.132 MUD for the untreated alloy (Fig. 6a). Some persistent preferential orientation is still visible towards the $\langle 10 \overline{1} 0\rangle$ direction after nitrogen diffusion treatment, but there is a significant decrease in texture from the untreated case, as indicated by the significantly lower measured texture intensities. Clearly, at longer nitriding durations (such as $48 \mathrm{~h}$ ) a significant degree of recrystallisation occurs and the grains have enough time to re-orient themselves, as evidenced by the relatively low maximum texture intensity of 3.879 MUD for this treatment (Fig. 6b). Such behaviour has also been reported by Garzón and Tschiptschin [37] for gas nitriding and is typically accompanied by grain growth. This phenomenon will be discussed later. The texture symmetry obtained for the untreated $\mathrm{Ti}-6 \mathrm{Al}-4 \mathrm{~V}$ is indicative of the warm extrusion process used during the manufacture of this alloy. This texture is termed basal/traverse $(\mathrm{B} / \mathrm{T})$ texture and is typical of low deformation temperatures in the $\alpha+\beta$ phase range [38].

Examination of EBSD phase composition presented in Table 4 shows that, following PIRAC treatment, the remaining principal constituent is $\alpha$-Ti. There are however some changes in the $\beta$ fraction when the treatment conditions are varied - while the $\beta$ presence for the treatment at $700{ }^{\circ} \mathrm{C}$ remains unchanged, following treatments at $800{ }^{\circ} \mathrm{C}$ and $900{ }^{\circ} \mathrm{C}$ an increase of more than 200 vol\% and $450 \mathrm{vol} \%$ respectively is measured compared to the untreated $\mathrm{Ti}$ alloy. Slip is known to occur more readily in beta phase rather than in alpha phase, owing to a shorter slip path typical of the bcc (beta) structure. The number of readily available slip systems in a bcc structure aid in relieving stresses more effectively than those in an hcp structure $[39,40]$. Cooling of titanium from the stable beta phase region tends to produce a duplex microstructure containing retained $\beta$-phase with the possibility of transformed $\beta$-phase which is known to favour prismatic and basal slip as opposed to a microstructure which contains solely basal slip systems typical of the $\alpha$-structure [41]. This microstructure leads to an increased amount of stress relieving slip systems, in turn leading to longer fatigue life $[38,40]$. Indeed, this may be an important contribution to the observed fatigue performance of the surface treated alloy; specifically for samples PIRAC nitrided at $800^{\circ} \mathrm{C}$ for $4 \mathrm{~h}$, which exhibit superior fatigue strength compared to those treated at a lower temperature $\left(700{ }^{\circ} \mathrm{C}\right)$ - thus having a lower $\beta$-fraction.

Grain size maps, together with grain diameter distribution charts for the alpha-phase (existing in both untreated (and PIRAC-treated $\mathrm{Ti}-6 \mathrm{Al}-4 \mathrm{~V}$ ) are presented in Fig. 7. In order to obtain a mean grain diameter value for the different samples, a mathematical method developed by Engqvist et al. [42] was used. This volume average method for grain size analysis provides representative mean grain size values closely corresponding to the grain area distribution plots which, unlike a simple numerical average, are not largely dependent on the number of grains sampled and/or the presence of very fine grains - some of which may be incorrectly indexed. The Engqvist method accounts for this 'noise' in the data without necessitating the introduction of arbitrary cut-off values for small grains, which are often used to 'clean' EBSD data. Furthermore, all edge grains - i.e. partial grains at the edge of the scan area - were omitted from this calculation.

An average grain size of $1.13 \pm 0.28 \mu \mathrm{m}$ was calculated for untreated Ti-6Al-4V (Fig. 7a). This is well within the typical range for $\alpha$-grain size in Ti-6Al-4V, which typically lies between 0.5 and $2.5 \mu \mathrm{m}$ [17]. After PIRAC treatment there is a measurable increase in mean grain size to $1.33 \pm 0.53 \mu \mathrm{m}$ and $2.27 \pm 0.68 \mu \mathrm{m}$ for the treatments performed at $800{ }^{\circ} \mathrm{C}$ and $900{ }^{\circ} \mathrm{C}$, respectively (Fig. $7 \mathrm{C}$ and d); i.e. increases of around 20\% and $100 \%$ respectively compared to the untreated case. Interestingly, for the treatment performed at $700{ }^{\circ} \mathrm{C}$ for $48 \mathrm{~h}$ (Fig. 7b), the average grain size was $3.22 \pm 0.82 \mu \mathrm{m}$, which is significantly larger than the average grain size following higher temperature treatment at $900{ }^{\circ} \mathrm{C}$. Grain growth under these conditions was not entirely uniform as both smaller $(\sim 0.8 \mu \mathrm{m})$ and larger $(\sim 6.5 \mu \mathrm{m})$ grains are observed which is wider than the reported range for the other treatments. This excessive grain growth for the $700{ }^{\circ} \mathrm{C}$ PIRAC treatment can be attributed to the longer nitriding duration of $48 \mathrm{~h}$. Moreover, the latter treatment exhibited uniform growth in all the grains while other PIRAC treatments led to a larger number of smaller diameter grains being retained within the microstructure. This significant amount of grain growth has a detrimental effect on the mechanical performance of the alloy [17].

\subsection{Rotating-bending fatigue testing}

The rotating-bending-fatigue results for the untreated and PIRAC-treated Ti-6Al-4V are shown in the form of $S-N$ plots in Fig. 8. The results for untreated Ti-6Al-4V presented in this plot are consistent with those previously reported in [5]. The fatigue limit appears to decrease following PIRAC nitrogen-diffusion.

Specimens treated at $800{ }^{\circ} \mathrm{C}$ for $4 \mathrm{~h}$ exhibit only a marginal reduction in high cycle fatigue (HCF) strength compared to untreated Ti-6Al-4V. The fatigue limit of untreated Ti-6Al-4V is $\sim 870 \mathrm{MPa}$ whilst the abovementioned treatment conditions led to a fatigue strength reduction of around $5 \%$. When performed at $700{ }^{\circ} \mathrm{C}$, PIRAC treating led to a larger drop in the fatigue limit. The lower temperature treated samples were clearly compromised by 
(a)

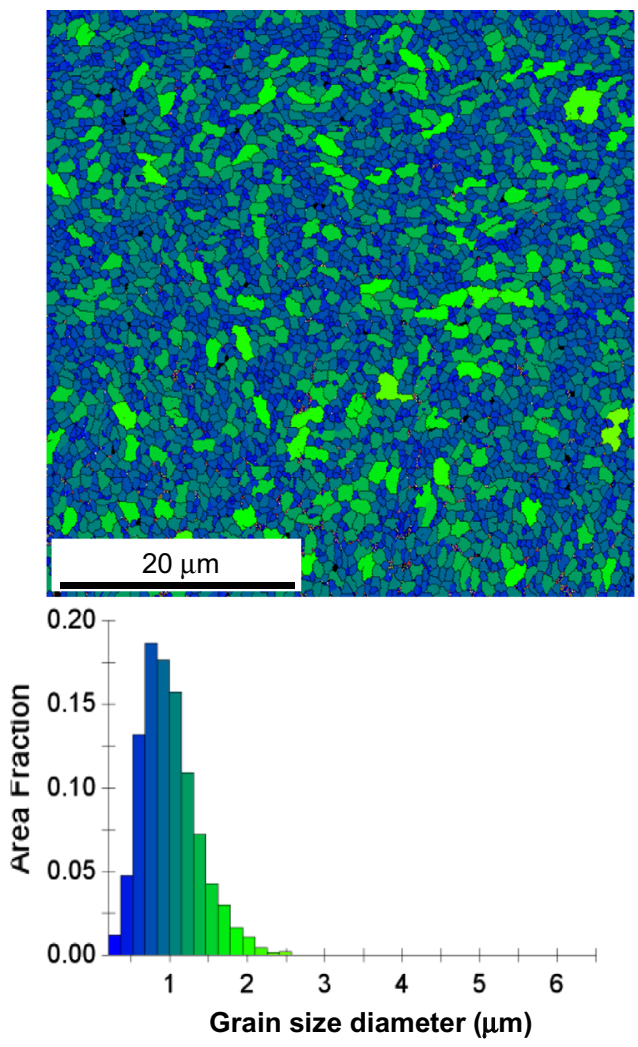

(c)

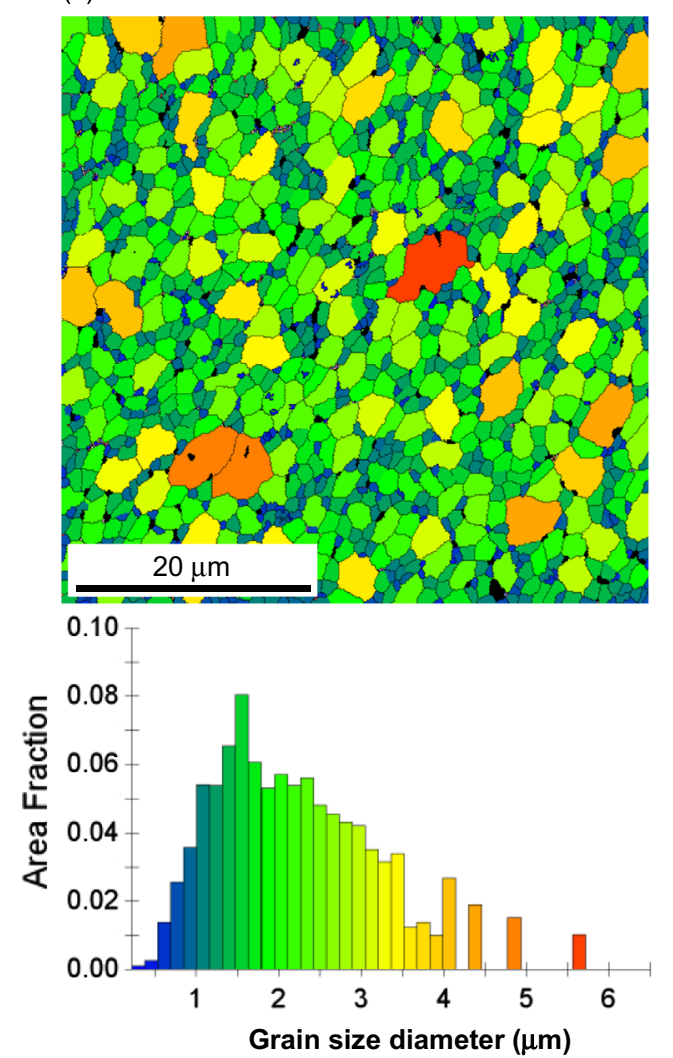

(b)

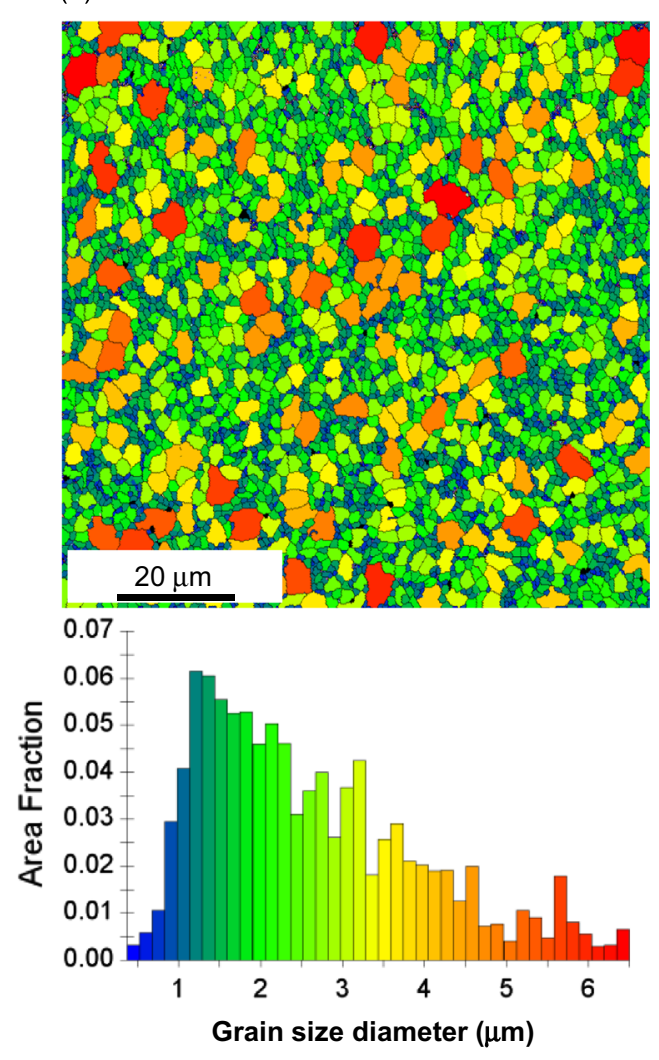

(d)
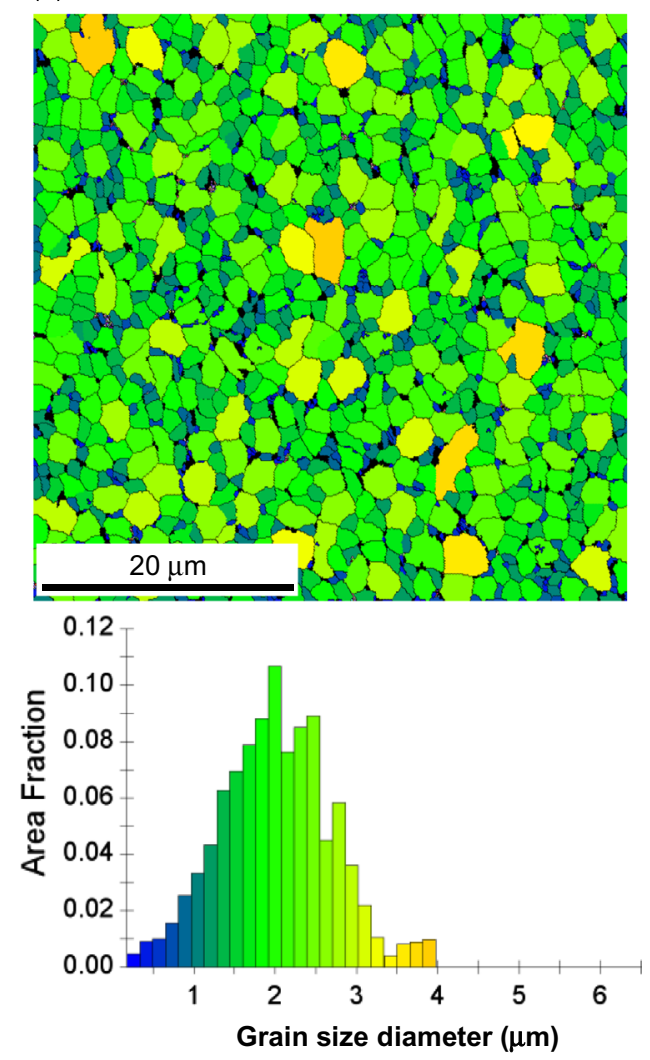

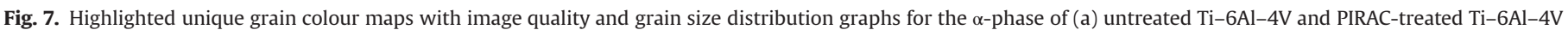

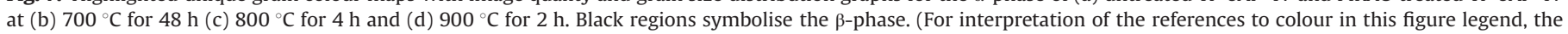
reader is referred to the web version of this article). 


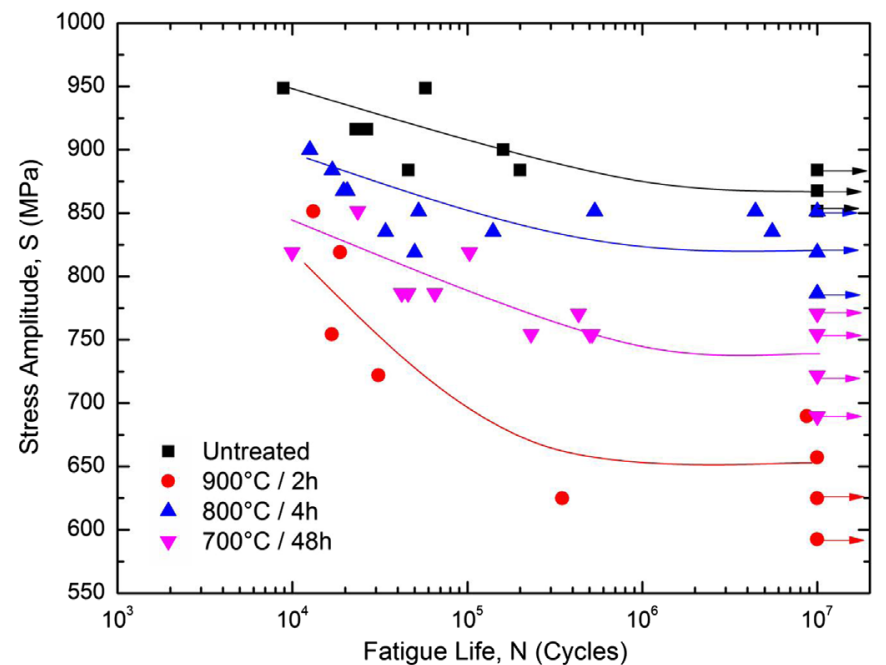

Fig. 8. $S-N$ diagram for untreated and PIRAC-treated Ti-6Al-4V coupons. Arrows indicate samples which survived more than $10^{7}$ cycles.

Table 5

Arithmetic mean height roughness, $S_{a}$, for untreated and PIRAC-treated Ti-6Al-4V at various processing parameters.

\begin{tabular}{|c|c|}
\hline Processing parameters & $\begin{array}{l}\text { Arithmetic mean height } \\
\text { roughness, } S_{a}(\mu \mathrm{m})\end{array}$ \\
\hline Untreated $\mathrm{Ti}-6 \mathrm{Al}-4 \mathrm{~V}$ & $0.081 \pm 0.005$ \\
\hline Temperature $\left({ }^{\circ} \mathbf{C}\right) \quad$ Duration $(h)$ & \\
\hline 700 & $0.151 \pm 0.005$ \\
\hline 800 & $0.132 \pm 0.006$ \\
\hline 900 & $0.265 \pm 0.020$ \\
\hline
\end{tabular}

the much longer diffusion treatment time of $48 \mathrm{~h}$. Finally, Ti-6Al$4 \mathrm{~V}$ samples exhibiting the largest decline in fatigue limit (approximately 25\%) were those treated at $900{ }^{\circ} \mathrm{C}$ for $2 \mathrm{~h}$, when compared to untreated Ti-6Al-4V. The improved performance in fatigue life for the treatments performed at $800{ }^{\circ} \mathrm{C}$ (as opposed to treatments at $700{ }^{\circ} \mathrm{C}$ and $900^{\circ} \mathrm{C}$ ) is attributed to the increased build-up of compressive residual surface stresses at $800{ }^{\circ} \mathrm{C}$ which inhibit crack propagation by resisting cyclic slip $[5,43]$. Moreover, longer plasma nitriding durations have been associated with recrystallisation and grain growth - which may lead to premature failure, decreasing the overall fatigue life [5]. Indeed, the treatment at $800{ }^{\circ} \mathrm{C}$ for $4 \mathrm{~h}$ was characterised by the second least increase in grain size out of all the PIRAC treatments studied in this work. Clearly, the fact that the fatigue results do not follow a trend dictated by grain size, suggests that other effects - such as surface roughness, the thickness and composition of the compound layer and the amount of $\alpha / \beta$ phase content in the substrate - are also at play. Necessarily, the compound layer characteristics would also affect the surface compressive stress state and the mode of crack initiation under cyclic loading.

Thermochemical diffusion processes are known to cause an increase in surface roughness $[22,44]$ depending on the type and severity of the operating conditions used. A larger increase in surface roughness is expected with higher temperatures and/or nitriding process durations. Furthermore, the formation of titanium aluminide intermetallics, such as the $\mathrm{Ti}_{3} \mathrm{Al}$ phase detected via GIXRD, has also been reported to increase surface roughness [45]. Essentially in a 'defect-free' material, most fatigue cracks originate from the free surface, therefore, a higher surface roughness accelerates the crack nucleation stage and increases the chances of a specimen not reaching the maximum endurance limit (which it would otherwise be able to withstand) [46].

$S_{a}$ areal roughness values for PIRAC-treated titanium alloy are tabulated in Table 5. The highest measurable $S_{a}$ value was for the $900{ }^{\circ} \mathrm{C}$, $2 \mathrm{~h}$ treatment $(0.265 \pm 0.020 \mu \mathrm{m})$ whereas the minimum was measured for the untreated condition $(0.081 \pm 0.005 \mu \mathrm{m})$. In the absence of residual compressive stress, a surface roughness in excess of $0.1 \mu \mathrm{m} R_{a}$ has been shown to have a strong influence on fatigue life [46]. Therefore, although the PIRAC treatment at $700{ }^{\circ} \mathrm{C}$ for $48 \mathrm{~h}$ resulted in a measurable average grain size $42 \%$ larger than the treatment performed at $900{ }^{\circ} \mathrm{C}$ for $2 \mathrm{~h}$, it yielded better fatigue strength results, owing to a twofold increase in the surface roughness for the latter treatment.

Fatigue behaviour is also influenced by case depth evolution, which is dependent on the nitrogen diffusion efficacy. It has been shown that the compound layer has less of a beneficial effect in extending the fatigue limit of nitrided samples than that of the underlying nitrogen diffusion zone [5]. This is related to the amount of nitrogen diffused in the sample bulk, where a fine dispersion of nitride precipitates hinders dislocation motion. For this reason thermochemical processes such as PIRAC nitrogen-diffusion may also be employed to interrupt the growth of nucleated cracks under the tensile part of the fatigue loading cycle. In fact, this effect (linked to the creation of surface compressive stresses) suppresses the propagation of surface-initiated cracks to the subsurface [43,47]. In the event that a surface crack progresses to the interior, it can otherwise cross grain boundaries unhindered, by changing from one slip system to another according to the new grain orientation [48]. Despite these beneficial effects, when strains are too high the mismatch in Young's moduli, $E$, between the substrate and the nitride layer (as reported in Table 3) may lead to early crack formation in the brittle nitride case [47].

The substrate microstructure has a determining role in the failure mode of the treated alloy. Coarsening of $\alpha$-grains with increasing treatment temperature (and duration) has been previously observed from EBSD mapping shown in Fig. 7. It is well known that the mechanical properties of a material are strongly dependent on the grain size. This dependence is traditionally represented by the HallPetch equation, in which: $\sigma_{y}=\sigma_{0}+k_{y} / \sqrt{d}$, where $\sigma_{y}$ is the yield strength, $d$ is the average grain diameter, and $\sigma_{0}$ and $k_{y}$ are constants for the material in question. This relationship infers that a fine grained material should exhibit a higher strength. A reduction in the primary $\alpha$ grain size affects the available slip length and can thus improve resistance to fatigue crack initiation [41]. Equiaxed grain structures typical of the Ti-6Al-4V alloy studied have a fine microstructure (as opposed to lamellar [49] and bi-modal microstructures), resulting in superior high cycle fatigue strength $[17,49]$ - which is a desirable feature for many dynamically-loaded structural components. It is therefore important that surface engineering processes to protect such components against corrosion and wear should yield a minimal amount of grain growth. Clearly, from the $S-N$ plots, the coupons exhibiting the largest yield strength (after the untreated case) are those subjected to the $800{ }^{\circ} \mathrm{C}, 4 \mathrm{~h}$ treatment, indicating that the overall grain coarsening is smaller than for the treatment at $700{ }^{\circ} \mathrm{C}, 48 \mathrm{~h}$ (so that the mean grain diameter is smaller at $800^{\circ} \mathrm{C}, 4 \mathrm{~h}$ ). The samples PIRAC-treated at $800{ }^{\circ} \mathrm{C}$ were also characterised by the smallest increase in surface roughness following nitriding (see Table 5).

From Fig. 6, it can be observed that PIRAC-treated samples present strong prismatic (1010) plane texturing. This implies that most of the grains are oriented with their $c$-axis perpendicular to the loading direction adopted in the rotating-bending fatigue test setup. Fatigue life is greatly dependant on the loading direction relative to the orientation of the $c$-axis of basal planes and in the literature it has been shown that loading perpendicularly to the $c$ axis leads to better fatigue life performance [50]. This is attributed to the increased availability of active slip systems, which assist in 
absorbing and releasing the strains produced during cyclic loading. The relationship between texture and loading is also pertinent to untreated Ti-6Al-4V.

The effect of grain orientation on fatigue-induced slip (which eventually leads to cracking) has also been studied in [41]. Slip occurs by the movement of dislocations in grains with favourable $a$-axis orientation, causing strain in directions parallel to the basal plane. Theoretically, the critical shear stress should increase for a grain oriented for $c+a$ slip and, as a consequence, grains oriented in this direction should be better able to arrest cracks. However, given that the applied stress is sufficient, slip and progressively cracking will occur in the $c+a$ direction of an hcp crystal, causing strain in the primary $c$-axis $[41,51]$. Strain in the $c$-axis is also known to be induced by twinning [51]. Some twinning could be clearly distinguished from EBSD analysis of PIRAC-treated coupons; however, due to large elastic strains induced during the fatigue test it is believed that $c+a$ slip is the predominant deformation mode. Contrary to this argument, from Table 4 there is an approximate $1.3 \%$ decrease in $\alpha$ fraction for treated coupons in comparison to the untreated substrate. This reduction in the amount of $\alpha$-phase means that the possibility for $c+a$ slip (and possibly twinning) is also decreased, supposedly increasing the crack initiation resistance in PIRAC-treated specimens. This decrease in $\alpha$-content upon increasing the nitriding time does not follow the trend dictated by the $S-N$ plot for rotatingbending fatigue testing in Fig. 8 . This means that the dependence of the fatigue performance on bulk material properties is superseded by other factors that are largely dependent on the treatment effect on the surface.

\subsection{Fracture topography}

The first analysis of fracture mode was carried out by optical imaging of selected fractured coupons, selected micrographs can be viewed in Fig. 9. When comparing multiple crack topographies, the
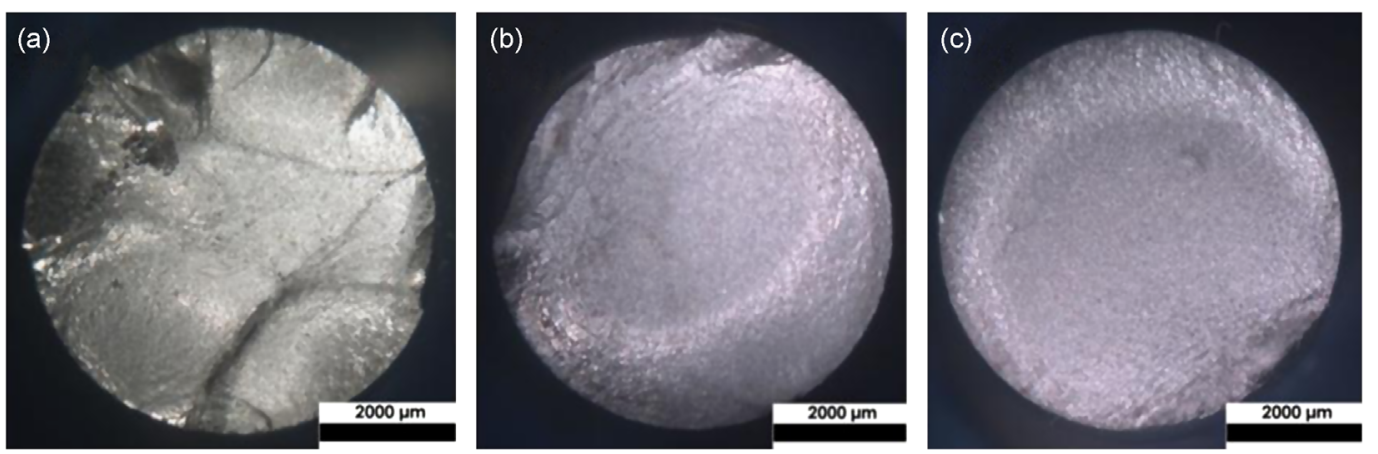

Fig. 9. OM fracture topographies for untreated Ti-6Al-4V (a) tested at a stress amplitude of $690 \mathrm{MPa}$ and surviving $2.05 \times 10^{6}$ cycles and (b) $950 \mathrm{MPa}$ and surviving $5.77 \times 10^{4}$ cycles and (c) PIRAC-treated Ti-6Al-4V at $900{ }^{\circ} \mathrm{C}$ for $2 \mathrm{~h}$ tested at a stress amplitude of $690 \mathrm{MPa}$ surviving $8.74 \times 10^{6}$ cycles.

(a)

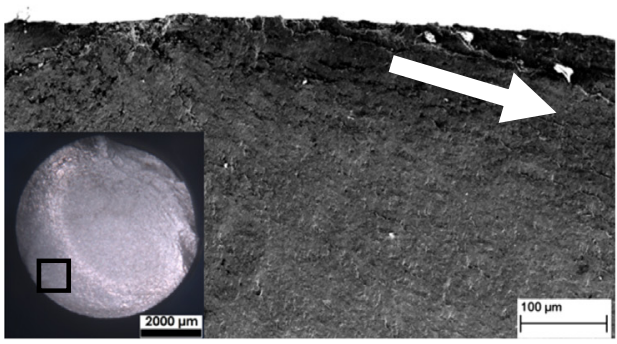

(c)

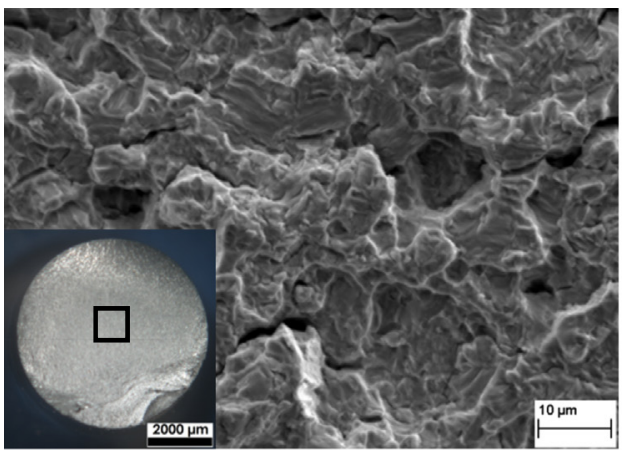

(b)

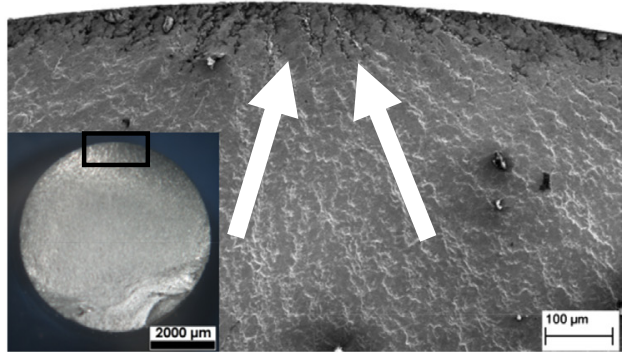

(d)

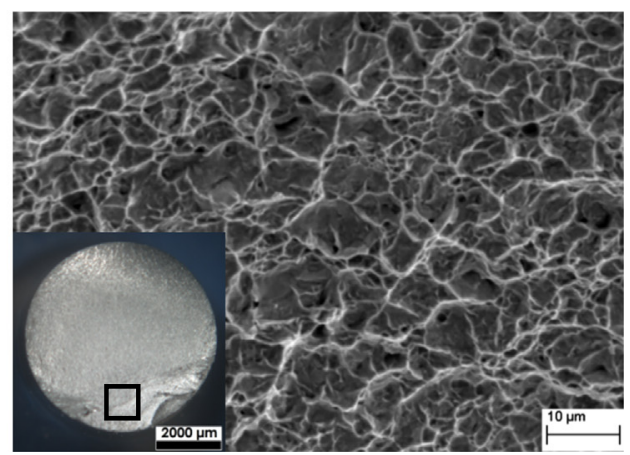

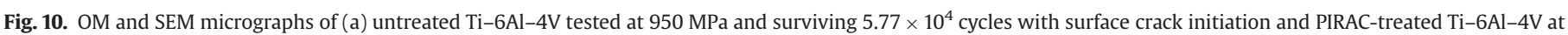

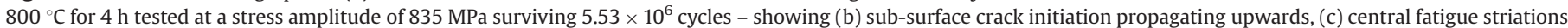
with secondary cracks and (d) tensile cracks in the shear lip. 
untreated sample (Fig. 9a) tested in the HCF region failed in the most uneven manner, with deep troughs and pronounced shear lip formations. Multiple crack initiation sites (generally described as 'cleavages') were observed for this coupon. An untreated sample that failed in the low-cycle fatigue (LCF) region had less deep troughs, indicating that the sample failed from a single initiation site (Fig. 9b). In comparison, all PIRAC-treated fatigue specimens (Fig. 9c) exhibited a uniform failure with no prominent peaks, troughs and deflections. This difference in failure mode can be related to a change in grain size. Larger grains lead to perpendicular markings at the fracture surface, indicating that failure was due to large cracks that initiated suddenly [52]. Particularly, in the HCF regime, fatigue strength is known to diminish drastically with increasing grain size due to premature and sudden crack formation [17].

Thermochemical processes such as nitriding and mechanical surface treatments such as shot peening, ball-burnishing and rollerburnishing are known to induce subsurface crack nucleation $[43,53,54]$. These form as a result of tensile stresses in the treatment/substrate interfacial regions, which balance out the compressive residual stresses induced in the surface by the diffusion process. It has also been argued that the greater the processaffected case depth (as in roller-burnishing), the deeper the location of the nucleation sites. It follows that there is no build-up of residual stress in untreated specimens and in this case cracks are seen to originate from the surface - possibly as a result of machining defects $[47,53]$.

The fractographs shown in Fig. 10a and b show that fracture originated from the surface for untreated Ti-6Al-4V (seen as a distinct ridge) while treated coupons were characterised by subsurface nucleation. In Fig. 10c central fatigue striations and secondary cracks can be seen, with some fissures forming at the edges of the striations. In Fig. 10d tensile cracks appear as dimples surrounded by tear ridges. Subsurface crack initiation is not a common failure mechanism for titanium alloys as they are known to be generally free from inclusions [53]. Some secondary cracks were observed for the treatment at $800{ }^{\circ} \mathrm{C}$ for $4 \mathrm{~h}$; these form as a result of the increase in surface roughness reported in Section 3.5. To summarise, fatigue crack formation in PIRAC diffusion-treated samples can be divided into three types: (i) transgranular brittle fracture in the nitrogen-treated layer (the first $50 \mu \mathrm{m}$ ) (ii) central fatigue striations and (iii) ductile fracture in the shear lip [47]. It was noted that crack propagation in the PIRAC diffusion-treated coupons follows a more irregular path than in the untreated specimens. This behaviour has been attributed to the fact that crack fronts are advancing in coarser grained material, as previously reported by Shibata et al. [52] and Tokaji et al. [55].

\section{Conclusions}

In this work, Ti-6Al-4V has been PIRAC nitrogen-diffusion treated under different processing parameters over a range of treatment temperatures and durations. GIXRD analysis shows that the post-treatment phases present in the compound layer include $\delta$-TiN, $\varepsilon-\mathrm{Ti}_{2} \mathrm{~N}$ and the $\mathrm{Ti}_{3} \mathrm{Al}$ intermetallic phase.

Compound layer thickness measurements using SEM showed that an increase in nitriding temperature (from $700{ }^{\circ} \mathrm{C}$ up to $900{ }^{\circ} \mathrm{C}$ ) provides the possibility of significantly reducing the nitriding time to obtain a comparable compound layer thickness.

PIRAC nitrogen-diffusion treatments at $900{ }^{\circ} \mathrm{C}, 2 \mathrm{~h}$ and $800^{\circ} \mathrm{C}$, $4 \mathrm{~h}$ present some persistent prismatic (1010) plane texturing, compared to the unprocessed microstructure, while longer treatment durations at $700{ }^{\circ} \mathrm{C}(48 \mathrm{~h})$ result in moderate texturing attributed to a shift towards larger grain diameters of $\sim 6.5 \mu \mathrm{m}$ for such treatment conditions.
All PIRAC-treated samples show some reduction in fatigue strength over untreated Ti-6Al-4V. Rotating-bending fatigue tests showed that processing temperature is not the only determining criterion that affects fatigue life. Treatment duration, posttreatment grain size, and degree of surface roughening all play an equally important role. In terms of nitriding duration, samples treated at $800{ }^{\circ} \mathrm{C}$ but for a shorter time, compared to the lower temperature $700{ }^{\circ} \mathrm{C}$ treatment, exhibited better fatigue performance. The PIRAC treatment performed for a short time $(2 \mathrm{~h})$ at $900{ }^{\circ} \mathrm{C}$ was characterised by smaller grain sizes than a treatment performed for a longer period $(48 \mathrm{~h})$ at $700{ }^{\circ} \mathrm{C}$; however, due to a marked increase in surface roughness, the samples treated at the higher temperature failed earlier.

Finally, out of the various PIRAC nitrogen-diffusion treatments tested, the one that gave the best fatigue performance on a $\mathrm{Ti}-$ $6 \mathrm{Al}-4 \mathrm{~V}$ substrate was $800{ }^{\circ} \mathrm{C}$ for $4 \mathrm{~h}$. This treatment produced a thin nitride compound layer and was accompanied by acceptably low grain growth, leaving the bulk high-cycle fatigue strength properties of Ti-6Al-4V largely intact.

\section{Acknowledgements}

The authors would like to thank the European Regional Development Fund (Malta) for research equipment funded through the application of the project "Developing an Interdisciplinary Material Testing and Rapid Prototyping R\&D Facility (Ref. no. 012)". The authors are also greatly indebted to MATERA+/ERA-NET Plus for funding support for this research (Project ESM-1935).

\section{References}

[1] A. Zhecheva, S. Malinov, W. Sha, Surf. Coat. Technol. 201 (2006) 2467-2474.

[2] M.J. Donachie Jr., Titanium: A Technical Guide, 2nd ed., ASM International, United States of America, 2000.

[3] G. Lütjering, J.C. Williams, Titanium, 2nd ed., Springer, Leipzig, Germany, 2007.

[4] M.A.Z. Vasconcellos, R. Hinrichs, C.S. Javorsky, G. Giuriatti, J.A.T. Borges da Costa, Surf. Coat. Technol. 202 (2007) 275-279.

[5] G. Cassar, J.C. Avelar-Batista Wilson, S. Banfield, J. Housden, M. Fenech, A. Matthews, A. Leyland, Int. J. Fatigue 33 (2011) 1313-1323.

[6] T.M. Manhabosco, S.M. Tamborim, C.B. dos Santos, I.L. Müller, Corros. Sci. 53 (2011) 1786-1793.

[7] A. Shenhar, I. Gotman, E.Y. Gutmanas, P. Ducheyne, Mater. Sci. Eng. A268 (1999) 40-46.

[8] A. Zhecheva, W. Sha, S. Malinov, A. Long, Surf. Coat. Technol. 200 (2005) 2192-2207.

[9] A. Shenhar, I. Gotman, S. Radin, P. Ducheyne, E.Y. Gutmanas, Surf. Coat Technol. 126 (2000) 210-218.

[10] Material Datasheet: TIMETAL 6-4 ${ }^{\mathbb{R}}$, Titanium Metals Corporation, Denver Colorado, United States of America, 2000.

[11] E.Y. Gutmanas, I. Gotman, W. Kaysser, Mater. Sci. Eng. A 157 (1992) $233-241$.

[12] I. Gotman, E.Y. Gutmanas, Mater. Lett. 10 (1991) 370-374.

[13] D. Starosvetsky, I. Gotman, Surf. Coat. Technol. 148 (2001) 268-276.

[14] W.C. Oliver, G.M. Pharr, J. Mater. Res. 7 (1992) 1564-1583.

[15] R.O.E. Vijgen, J.H. Dautzenberg, Thin Solid Films 270 (1995) 264-269.

[16] V. Randle, O. Engler, Introduction to Texture Analysis: Macrotexture, Microtexture and Orientation Mapping, CRC Press, Boca Raton, Florida, United States of America, 2000.

[17] G. Wu, C. Shi, W. Sha, A. Sha, H. Jiang, Mater. Des, 46 (2013) 668-674.

[18] ISO 1143 Metallic Materials - Rotating Bar Bending Fatigue Testing, International Organization for Standardization, Switzerland, 2010, pp. 1-26.

[19] A. Wöhler, J. Constr. Eng. 4 (1867) 160-161.

[20] Y.-L. Lee, D. Taylor, Stress-based fatigue analysis and design, in: Y.-L. Lee (Ed.), Fatigue Testing and Analysis, Butterworth-Heinemann, United States of America, 2005.

[21] F.G. Pascual, W.O. Meeker, Technometrics 41 (1999) 277-289.

[22] V. Fouquet, L. Pichon, M. Drouet, A. Straboni, Appl. Surf. Sci. 221 (2004) $248-258$.

[23] J. Niu, W. Wang, S. Zhu, F. Wang, Corros. Sci. 58 (2012) 115-120.

[24] H. Lee, H. Kang, J. Kim, H.-K. Shin, J. Lee, S.-H. Huh, J. Sung, H.-J. Lee, Surf. Coat Technol. 240 (2014) 221-225.

[25] D.B. Lee, I. Pohrelyuk, O. Yaskiv, J.C. Lee, Nanoscale Res. Lett. 7 (2012) 21

[26] R. Chattopadhyay, Surface characterization, in: Surface Wear: Analysis, Treatment, and Prevention, ASM International, USA, 2001. 
[27] C. Ruset, E. Grigore, G.A. Collins, K.T. Short, F. Rossi, N. Gibson, H. Dong, T. Bell, Surf. Coat. Technol. 174-175 (2003) 698-703.

[28] A. Lousa, J. Esteve, J.P. Mejia, A. Devia, Vacuum 81 (2007) 1507-1510.

[29] G.B. de Souza, C.E. Foerster, S.L.R. da Silva, F.C. Serbena, C.M. Lepienski, C.A. dos Santos, Surf. Coat. Technol. 191 (2005) 76-82.

[30] G. Abadias, S. Dub, R. Shmegera, Surf. Coat. Technol. 200 (2006) 6538-6543.

[31] E. Török, A.J. Perry, L. Chollet, W.D. Sproul, Thin Solid Films 153 (1987) 37-43.

[32] C. Martini, L. Ceschini, Tribol. Int. 44 (2011) 297-308.

[33] A. Leyland, A. Matthews, Wear 246 (2000) 1-11.

[34] M. Moravej, S. Amira, F. Prima, A. Rahem, M. Fiset, D. Mantovani, Mater. Sci. Eng. B 176 (2011) 1812-1822.

[35] M. Whittaker, P. Jones, C. Pleydell-Pearce, D. Rugg, S. Williams, Mater. Sci. Eng. A 527 (2010) 6683-6689.

[36] Y.N. Wang, J.C. Huang, Mater. Chem. Phys. 81 (2003) 11-26.

[37] C. Garzón, A. Tschiptschin, Mater. Sci. Eng. A 441 (2006) 230-238.

[38] G. Lütjering, Mater. Sci. Eng. A 243 (1998) 32-45.

[39] J.C. Williams, G. Lütjering, in: Fourth International Conference on Titanium, Metallurgical Society of AIME, Kyoto, Japan, 1980, pp. 671-681.

[40] C. Leyens, M. Peters, Titanium and Titanium Alloys: Fundamentals and Applications, 1st ed., Wiley, Darmstadt, Germany, 2003.

[41] I. Bantounas, T.C. Lindley, D. Rugg, D. Dye, Acta Mater. 55 (2007) 5655-5665.

[42] H. Engqvist, B. Uhrenius, Int. J. Refract. Met. Hard Mater. 21 (2003) 31-35.

[43] A. Alsaran, I. Kaymaz, A. Çelik, F. Yetim, M. Karakan, Surf. Coat. Technol. 186 (2004) 333-338.
[44] A.D. Wilson, A. Leyland, A. Matthews, Surf. Coat. Technol. 114 (1999) 70-80.

[45] H. Garbacz, J.M. Pouquet, E. García-Lecina, M. Díaz-Fuentes, P. Wieciński, R.H. Martin, T. Wierzchoń, K.J. Kurzydlowski, Surf. Coat. Technol. 205 (2011) 4433-4440.

[46] D. Novovic, R.C. Dewes, D.K. Aspinwall, W. Voice, P. Bowen, Int. J. Mach. Tool Manuf. 44 (2004) 125-134.

[47] D. Rodríguez, J.M. Manero, F.J. Gil, J.A. Planell, J. Mater. Sci. Mater. Med. 12 (2001) 935-937.

[48] H. Knobbe, P. Köster, H.J. Christ, C.P. Fritzen, M. Riedler, Procedia Eng. 2 (2010) 931-940.

[49] R. Nalla, B. Boyce, J. Campbell, J. Peters, R. Ritchie, Metall. Mater. Trans. A 33 (2002) 899-918.

[50] M.R. Bache, W.J. Evans, B. Suddell, F.R.M. Herrouin, Int. J. Fatigue 23 (Suppl. 1) (2001) 153-159.

[51] G.J. Baxter, W.M. Rainforth, L. Grabowski, Acta Mater. 44 (1996) 3453-3463.

[52] H. Shibata, K. Tokaji, T. Ogawa, C. Hori, Int. J. Fatigue 16 (1994) 370-376.

[53] A. Drechsler, J. Kiese, L. Wagner, in: A. Nakonieczny (Ed.), Proceedings of the 7th International Conference on Shot Peening, Institute of Precision Mechanics, Warsaw, 1999, pp. 145-152.

[54] L. Wagner, T. Ludian, M. Wollmann, in: S. Pantelakis, C. Rodopoulos (Eds.), Engineering Against Fracture: Proceedings of the 1st Conference, Springer Netherlands, Patras, Greece, 2009, pp. 1-11.

[55] K. Tokaji, T. Ogawa, H. Shibata, Int. J. Fatigue 16 (1994) 331-336. 